\title{
Genetic analysis of the breeding system of an invasive subterranean termite, Reticulitermes santonensis, in urban and natural habitats
}

\author{
STÉPHANIE DRONNET,${ }^{*}$ MICHEL CHAPUISAT, †EDWARD L. VARGO,‡ \\ CAROLINE LOHOUß and ANNE-GENEVIÈVE BAGNÈRES* \\ *Institut de Recherche sur la Biologie de l'Insecte, UMR CNRS 6035, Faculté des Sciences et Techniques, Université François Rabelais, \\ 37200 Tours, France, †Department of Ecology and Evolution, University of Lausanne, CH-1015 Lausanne, Switzerland, $\ddagger$ Department \\ of Entomology, Box 7613, North Carolina State University, Raleigh, NC 27695-7613, USA, §Circonscription des Etudes végétales, \\ Direction des Parcs, Jardins et Espaces Verts, Ville de Paris, France
}

\begin{abstract}
Reticulitermes santonensis is a subterranean termite that invades urban areas in France and elsewhere where it causes damage to human-built structures. We investigated the breeding system, colony and population genetic structure, and mode of dispersal of two French populations of $R$. santonensis. Termite workers were sampled from 43 and 31 collection points, respectively, from a natural population in west-central France (in and around the island of Oléron) and an urban population (Paris). Ten to 20 workers per collection point were genotyped at nine variable microsatellite loci to determine colony identity and to infer colony breeding structure. There was a total of 26 colonies, some of which were spatially expansive, extending up to 320 linear metres. Altogether, the analysis of genotype distribution, $F$-statistics and relatedness coefficients suggested that all colonies were extended families headed by numerous neotenics (nonwinged precocious reproductives) probably descended from pairs of primary (winged) reproductives. Isolation by distance among collection points within two large colonies from both populations suggested spatially separated reproductive centres with restricted movement of workers and neotenics. There was a moderate level of genetic differentiation $\left(F_{\mathrm{ST}}=0.10\right)$ between the Oléron and Paris populations, and the number of alleles was significantly higher in Oléron than in Paris, as expected if the Paris population went through bottlenecks when it was introduced from western France. We hypothesize that the diverse and flexible breeding systems found in subterranean termites pre-adapt them to invade new or marginal habitats. Considering that $R$. santonensis may be an introduced population of the North American species $R$. flavipes, a breeding system consisting primarily of extended family colonies containing many neotenic reproductives may facilitate human-mediated spread and establishment of $R$. santonensis in urban areas with harsh climates.
\end{abstract}

Keywords: dispersal, inbreeding, Isoptera, microsatellites, Rhinotermitidae, social organization, urban invasion

Received 14 December 2004; revision accepted 20 January 2005

\section{Introduction}

Biological invasions are often human-facilitated and commonly create serious economic and environmental problems (Everett 2000; Pimentel et al. 2000; Chapman \& Bourke 2001).

Correspondence: A.-G. Bagnères, Fax: (33) 247 367356; E-mail: bagneres@univ-tours.fr
Some social insect species have been highly successful in invading new regions (Moller 1996). In social insects, successful spread of invasive species largely depends on its breeding system (sensu Ross 1993) and mode of dispersal (Chapman \& Bourke 2001; Ross 2001; Holway et al. 2002). The number of reproductives within a colony, the mating system, modes of colony founding and dispersal all will affect the propensity to spread in and monopolize new 
habitats. In turn, arrival in a new environment may sometimes lead to an alteration in the breeding system. This might be due to new ecological conditions, such as an absence of competitors or parasites (Porter et al. 1997), or to genetic changes that take place during the introduction, such as a loss of nestmate recognition cues (Ross et al. 1996; Tsutsui et al. 2000, 2003; Chapman \& Bourke 2001; Giraud et al. 2002). Therefore, detailed investigation of the breeding system of invasive social insects is fundamental to further our understanding of how social structure, dispersal, and invasion success may be linked.

In termites (Isoptera), the genera Coptotermes and Reticulitermes are prominent groups of subterranean termite pests (Rhinotermitidae); they commonly infest humanbuilt structures where they may cause extensive damage (Gay 1969; Su \& Scheffrahn 1990). A population of subterranean termites is comprised of distinct colonies. Colonies may occupy underground networks that link several foraging sites (Thorne et al. 1999). The breeding system and mode of dispersal of Reticulitermes species is complex. Colonies are generally initiated by a single pair of primary (winged) reproductives, which results in a simple-family structure (one queen, one unrelated king and their progeny). Because winged reproductives can fly relatively long distances, this mode of colony initiation can result in high levels of gene flow across large spatial scales. Later in the colony life cycle, secondary reproductives, which develop from either brachypterous nymphs or from workers (reviewed in Lainé \& Wright 2003), can supplement or replace the primary reproductives. They are larvae instars, called neotenics. Neotenics do not fly, they remain and mate in the nest, resulting in inbreeding within colonies. Colonies headed by multiple neotenics can grow and expand, sometimes forming spatially diffuse networks of interconnected reproductive centres. Colony fragments can also become autonomous units that will constitute new colonies (Thorne et al. 1999). This 'budding' and limited dispersal would result in local isolation by distance, or 'population viscosity' (Hamilton 1964). The capacity to generate new colonies from colony fragments has also likely facilitated the spread of subterranean termites by human-mediated transportation of infested pots containing plants or timber. Thus, the diversity in breeding systems may facilitate colonization and invasion of novel environments by subterranean termites. On the one hand, once established they can produce long-range dispersers, on the other hand, they can profit from human transportation and build up populous colonies in localized areas.

The European subterranean termite Reticulitermes santonensis Feytaud is a severe structural pest in several parts of France, where it has been present in urban areas since at least the 18th century (de Quatrefages 1843). R. santonensis is a suspected introduced population(s) of the American species Reticulitermes flavipes (Feytaud 1924), which is sup- ported by their qualitative similarity in cuticular hydrocarbon profiles (although they appear to differ slightly in the composition of soldier defense compounds; Bagnères et al. 1990) and by molecular genetic data (Clément et al. 2001; Jenkins et al. 2001; Austin et al. 2002; Marini \& Mantovani 2002; Luchetti et al. 2004; Uva et al. 2004; Ye et al. 2004). Moreover, Dronnet et al. (2004) found that French populations of $R$. santonensis averaged fewer alleles and had lower heterozygosity than North American populations of $R$. flavipes at 11 microsatellite loci, which is consistent with a genetic bottleneck during the introduction of these termites from North America to France. The distribution of $R$. santonensis is also consistent with human introduction and spread in France because all populations are located in or close to buildings (Vieau 1993), with only a few small populations found in forests bordering the Atlantic Ocean (Vieau 2001). In addition, the populations in forest areas are close to the ports of La Rochelle and Nantes, some potential introduction sites. Invasion of new cities was probably facilitated by the development of railway transport of wood materials at the end of the 19th century, as suggested by the high incidence of infested areas near railway stations in large cities (Vieau 1993). In Paris, the species was first officially reported at the beginning of the 1950s, where termites are mostly found in buildings, but damage on trees along streets has also been observed for the last 10 years (Lohou et al. 1997).

The successful spread of $R$. santonensis seems associated with a high proportion of neotenic reproduction, as suggested by data on caste proportions (Vieau 1996), large spatial foraging range (Paulmier et al. 1997), and allozyme markers (Clément 1981). However, the breeding system of this species is still poorly known because of its cryptic lifestyle and underground foraging habits. In this study, we investigated the breeding system and mode of dispersal of $R$. santonensis using microsatellite markers. We analysed colony and population genetic structure in natural and urban regions in order to determine the prevalence of neotenic reproduction and improve our understanding of the factors facilitating the spread of subterranean termites to new urban areas.

\section{Materials and methods}

\section{Sampling}

Samples of Reticulitermes santonensis were collected in two contrasting habitats, a natural pine forest on or near the island of Oléron, and an urban region in the city of Paris. To obtain data both at the population and colony levels, we used a hierarchical sampling scheme, with single collection points over a large geographical scale $(>1 \mathrm{~km})$ and multiple collection points within a few selected sites (c. $300 \mathrm{~m})$.

Termites from the Oléron region were collected in April 2002 in 100-year-old pine forests, with stumps and 
(a)
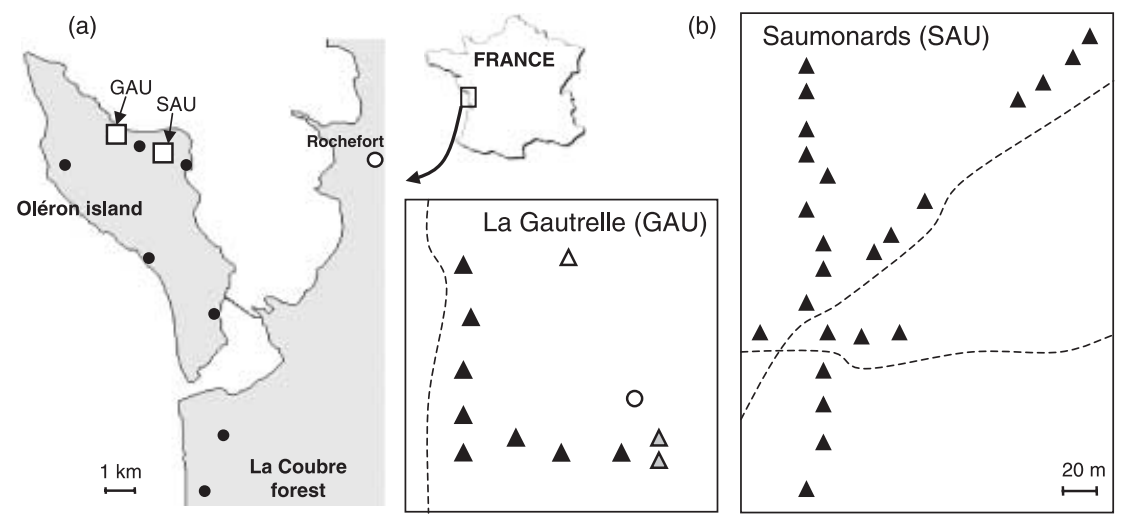

(a)

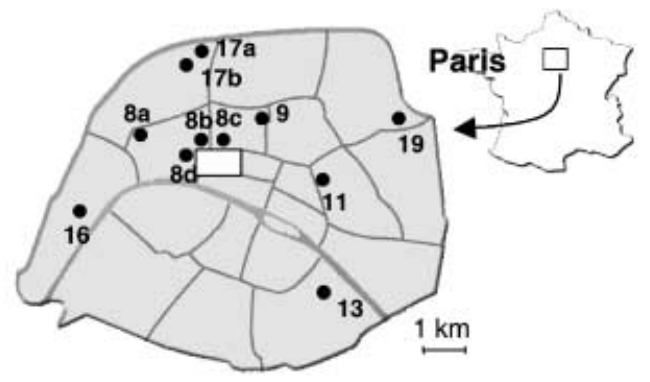

(b)

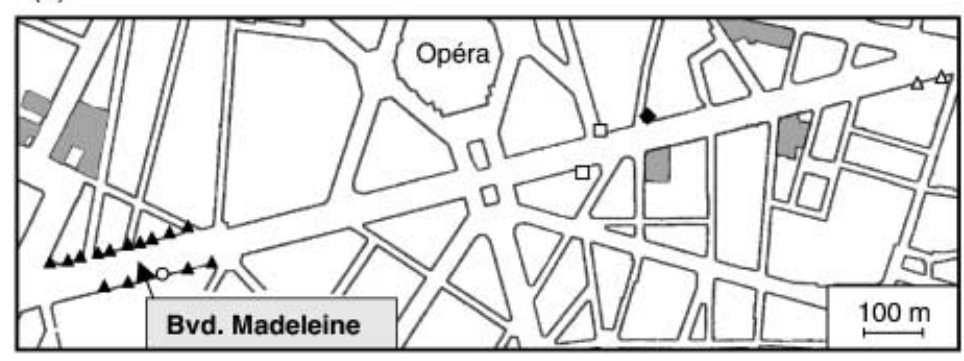

Fig. 1 Map of sample locations in the Oléron region (a), with an enlargement of the extensively sampled sites. (b) Collection points that were genetically nondifferentiated are indicated by the same symbols. Dashed lines represent forest paths.
Fig. 2 Map of sample locations in Paris (a) (the numbers correspond to the different arrondissements where termites where collected), with an enlargement of the extensively sampled site. (b) Collection points along the boulevards that were genetically nondifferentiated are indicated by the same symbols. The grey areas indicate known infested buildings close to the sampling sites. occasionally evergreen oaks. Five collection points were on the island of Oléron and two were in the continental forest of La Coubre, close to the southern tip of the island (Fig. 1a). Ten workers were sampled in each collection point (e.g. one stump). At a smaller scale, two other sites on the island of Oléron were sampled extensively (Fig. 1b), with 10 workers taken from collection points located every $20 \mathrm{~m}$ along two intersecting transects. Twenty-four stumps were sampled in the 'Saumonards' forest (SAU, $280 \times 320 \mathrm{~m}$ transects), and 12 stumps were sampled in 'La Gautrelle' forest (GAU, $100 \times$ $100 \mathrm{~m}$ ). These two sites are separated by $2 \mathrm{~km}$. In total, termites from 43 collection points were analysed in the Oléron region.

Termites were collected in September 2001 from 11 collection points within the city of Paris (Fig. 2a, b). At each collection point, 10-20 workers were sampled per building. At a smaller scale, one other site was sampled extensively (Fig. 2b), with 10 termites sampled from each of 15 trees regularly spaced approximately every $20 \mathrm{~m}$ lining Boulevard de la Madeleine (MAD, 8th arrondissement), and five more trees located 500 and $800 \mathrm{~m}$ away along the boulevard. To avoid damaging trees, termites were taken from mud tubes on the bark. In total, termites from 31 collection points were analysed in Paris.

The geographical scale of sampling was quite similar in the two regions, spreading over $14 \times 11 \mathrm{~km}$ in Oléron (excluding samples from La Coubre) and $10 \times 9.2 \mathrm{~km}$ in Paris. Immediately following collection, all workers from each collection point were placed in $95 \%$ ethanol and stored at $4{ }^{\circ} \mathrm{C}$ until DNA extraction.

\section{Microsatellite genotyping}

DNA was extracted from whole worker bodies using standard phenol-chloroform purification (Sambrook et al. 1989). In total, we determined the microsatellite genotypes of 430 termites from 43 collection points in the Oléron region and 390 termites from 31 collection points in Paris. We used nine microsatellite loci (Table 1): four loci originally isolated from R. flavipes (Rf1-3, Rf6-1, Rf11-1 and Rf15-2; Vargo $2000)$ and five loci characterized from $R$. santonensis ( $R S 10$, 
Table 1 Variability at nine microsatellite markers in Oléron region and Paris. The number of alleles and gene diversity $\left(H_{\mathrm{S}}\right)$ were calculated from the entire sample

\begin{tabular}{|c|c|c|c|c|}
\hline \multirow[b]{2}{*}{ Locus } & \multicolumn{2}{|c|}{$\begin{array}{l}\text { Oléron region ( } n=430 \text { individuals, } \\
43 \text { collection points, } 12 \text { colonies) }\end{array}$} & \multicolumn{2}{|c|}{$\begin{array}{l}\text { Paris ( } n=390 \text { individuals, } \\
31 \text { collection points, } 14 \text { colonies) }\end{array}$} \\
\hline & No. of alleles & Gene diversity $H_{\mathrm{S}}$ & No. of alleles & Gene diversity $H_{\mathrm{S}}$ \\
\hline Rf1-3 & 6 & 0.54 & 2 & 0.33 \\
\hline$R f 6-1$ & 9 & 0.42 & 6 & 0.49 \\
\hline Rf11-1 & 4 & 0.40 & 3 & 0.46 \\
\hline Rf15-2 & 4 & 0.37 & 2 & 0.46 \\
\hline RS10 & 5 & 0.35 & 4 & 0.39 \\
\hline RS15 & 4 & 0.40 & 4 & 0.64 \\
\hline RS68 & 3 & 0.18 & 3 & 0.26 \\
\hline RS76 & 3 & 0.20 & 2 & 0.40 \\
\hline RS85 & 4 & 0.19 & 2 & 0.32 \\
\hline Mean $( \pm$ SD) & $4.7 \pm 1.9$ & & $3.1 \pm 1.4$ & \\
\hline Overall & & 0.34 & & 0.42 \\
\hline
\end{tabular}

RS15, RS68, RS76 and RS85; Dronnet et al. 2004). Two additional markers, one from $R$. flavipes (Rf11-2; Vargo 2000) and one from $R$. santonensis (RS93; Dronnet et al. 2004) had to be discarded because they were difficult to score and had spurious bands. Polymerase chain reaction (PCR) amplifications were performed as described in Dronnet et al. (2004). PCR products were separated by electrophoresis on $6 \%$ polyacrylamide gels run on a LI-COR $4000 \mathrm{~L}$ sequencer. Alleles were scored using the computer program GENE PROFILER 4.03 (Scanalytics, Inc.).

\section{Genetic data analysis}

We first examined whether the collection points belonged to the same colony or not. We compared the genotypic frequencies between all pairs of collection points by means of a log-likelihood $(G)$ based test of differentiation using the program GENEPOP on the Web (Raymond \& Rousset 1995; http://wbiomed.curtin.edu.au/genepop/index.html). The overall significance was determined via Fisher's combined probability test. A Bonferroni correction was applied to account for multiple comparisons. Samples from two collection points were considered to belong to different colonies when genotypic differentiation was statistically significant, and grouped into the same colony when it was not. Admittedly, this procedure can lead to false assignments in cases in which genetic contrasts among colonies are small, such as in populations with low overall genetic diversity or high genetic diversity within colonies. However, G-tests have proven useful and are widely used to delineate colonies of social insects, which is an indispensable step for performing further analyses (Vargo 2003a, b; DeHeer \& Vargo 2004).

We carried out this $G$-test analysis with collection points over a large spatial scale, then with multiple collection points within the extensively sampled sites, and finally among the colonies from each population to verify the genetic differences.

Once colony boundaries were defined, we investigated the breeding system of single colonies. We classified colonies as simple or extended families by comparing the observed genotypes of workers within colonies with the genotypes expected in these types of societies by using standard criteria for termites (Bulmer et al. 2001; Goodisman \& Crozier 2002; Vargo 2003a, b; DeHeer \& Vargo 2004). First, colonies could be classified as simple families when workers had genotypes consistent with being the direct offspring of one pair of reproductives, and when the observed frequencies of the genotypes did not differ significantly from those expected under Mendelian segregation of alleles from two parents. Significance was determined by a $G$-test $(P<0.05)$ combined across all loci. Second, colonies could be considered as extended families when the genotype distributions within colonies were not consistent with being produced by a single pair of reproductives (e.g. more than four genotypes at a locus or three or more homozygote genotypes), or genotype frequencies deviated significantly from those expected in simple families.

Genetic relatedness among workers was estimated for each colony and averaged over colonies of the same site using the computer program RELATEDNESs 5.00 (Queller \& Goodnight 1989). The standard errors of the means were obtained by jackknifing over colonies. For the allelic frequencies and the average relatedness estimates, colonies were weighted equally. The Oléron and Paris regions were analysed separately because we found some genetic differentiation between these distant sites (see Results), which would tend to inflate genetic relatedness among nestmates. Because inbreeding and/or spatial genetic differentiation increase measures of genetic relatedness above what is caused by close pedigree links (Pamilo 1985, 1989), we also calculated an inbreeding-adjusted estimate of relatedness 
$r^{*}$ that better reflects the number of reproductives present in each colony by using Pamilo (1985) formula $r^{*}=r-$ $\left[2 F_{\mathrm{IT}} /\left(1+F_{\mathrm{IT}}\right)\right] /\left[1-2 F_{\mathrm{IT}} /\left(1+F_{\mathrm{IT}}\right)\right]$.

The breeding system and genetic differentiation among colonies were further investigated with hierarchical $F$ statistics, assuming the infinite allele model and with individuals nested in colonies (Wright 1951; Weir \& Cockerham 1984; Weir 1996). Again, the Oléron region and Paris were analysed separately. The hierarchical analysis was performed with the computer program FSTAT 2.9.3.2 (Goudet 1995; http://www2.unil.ch/izea/softwares/fstat.html). Our F-statistics followed the notation of Thorne et al. (1999), with the subscripts I, C and T representing the individual, colony, and total components of genetic variation, respectively. The $95 \%$ confidence intervals were obtained by bootstrapping over loci 15000 times, and the significance of the coefficients was further tested by permuting alleles among individuals within colonies for $F_{\mathrm{IC}}$, alleles among colonies for $F_{\mathrm{IT}}$, and finally genotypes among colonies for $F_{\mathrm{CT}}$ (1000 permutations). In this special application at the colony level, the overall inbreeding coefficient $\left(F_{\mathrm{IT}}\right)$ reflects the deficiency of heterozygotes because of nonrandom mating within the total samples in Oléron region and Paris, respectively. $F_{\mathrm{CT}}$ estimates the amount of genetic differentiation (allele frequency differences) among colonies. $F_{\text {IC }}$ provides information on the number of reproductives and relatedness among them. It is expected to be strongly negative in simple families headed by a pair of reproductives (Thorne et al. 1999). $F_{\text {IC }}$ approaches zero with increasing numbers of reproductives and becomes positive in various cases: if there is assortative mating among multiple reproductives within colonies or if workers come from genetically differentiated colonies which have either fused together or which share foraging tunnels in common (Thorne et al. 1999). We inferred the likely breeding system of $R$. santonensis by comparing our empirical F-statistics and relatedness values to those of Thorne et al. (1999) and Bulmer et al. (2001) generated by computer simulations.

We investigated whether there was isolation by distance (a positive correlation between genetic differentiation and geographical distance) by calculating $F_{\mathrm{ST}}$ between pairs of collection points within large colonies using the computer program FSTAT 2.9.3.2, and by testing the significance of the correlation between $F_{\mathrm{ST}} /\left(1-F_{\mathrm{ST}}\right)$ and the logarithm of geographical distances (Slatkin 1993; Rousset 1997) with Mantel tests (Mantel 1967). We used the computer program GENEPOP, with 10000 permutations, and the Mantel correlation coefficient $r$ was obtained with MANTEL for Windows 1.15 (http://life.bio.sunysb.edu/morph/soft-mult.html).

We tested whether the populations from Oléron and Paris were genetically differentiated in a three-level hierarchical $F$-statistics, with individuals nested in colonies and colonies nested in region (Oléron or Paris, respectively), as implemented in the computer program GENETIC DATA ANALYSIS (Lewis \&
Zaykin 2000). The confidence interval of the $F_{\mathrm{ST}}$ between Oléron and Paris was determined by bootstrapping over loci.

Finally, we compared the number of alleles per locus between the two regions using a $t$-test, and we estimated gene diversity (Nei 1987) in the Oléron region and Paris city using FSTAT. The significance of the difference in gene diversity was estimated by permuting colonies between the two regions, as implemented in FSTAT (1000 permutations, two-tailed tests).

\section{Results}

\section{Colony identification}

The samples from the seven collection points of the Oléron region were all genetically differentiated ( $G$-test of differentiation between pairs of collection point, all $P<0.0001$ ), indicating that they belonged to different colonies (Fig. 1a).

The analysis at the smaller spatial scale, in the Saumonards site, revealed that workers from all of the 24 collection points belonged to a single colony that encompassed a very large area of almost $90000 \mathrm{~m}^{2}$ (Fig. $1 \mathrm{~b}$ and $280 \times 320 \mathrm{~m}$, Gtest, all $P>0.05)$. This area appeared to be a distinct entity, because just outside of this sampling area we could not find stumps containing termites. In contrast, workers from the 12 collection points in the La Gautrelle site belonged to four distinct colonies of much smaller size (Fig. 1b, G-test, $P>0.05$ among two and eight collection points, respectively, while $P<0.0001$ among all other collection points).

Hence, in the Oléron region, 12 colonies were identified because they were genetically differentiated from each other (G-test, all $P<0.05)$ and were included in further analyses of the breeding system and colony genetic structure.

Within Paris, there was significant differentiation among most of the 11 collection points from buildings (Gtest: $P<0.0001$ ), and these collection points were therefore considered to belong to nine different colonies. Indeed, some collection points (17th arrondissement: $17 \mathrm{a}$ and $17 \mathrm{~b}$; 8th arrondissement: $8 b$ and $8 c$, see Fig. 2) in buildings were not genetically differentiated and were considered to belong to two colonies spreading over at least 190 and $175 \mathrm{~m}$, respectively (G-test, $P=0.53$ and 0.72 ). Surprisingly, neither $8 \mathrm{~b}$ nor $8 \mathrm{c}$ were differentiated from another collection point ( $8 \mathrm{a}$ ) located $2 \mathrm{~km}$ west ( $G$-test, $P=0.89$ and 0.82 , Fig. 2). The distant collection point 8 a was nevertheless considered to be a different colony, because it is very unlikely that it was connected to $8 \mathrm{~b}$ and $8 \mathrm{c}$ by foraging tunnels in such a complex urban environment.

At a smaller scale, 14 trees along Boulevard de la Madeleine were attacked by a single large colony that spreads over $30000 \mathrm{~m}^{2}$, as revealed by nonsignificant differentiations among pairs of collection points ( $G$-test, all $P>0.05$, full triangles). Termites from a single tree in the middle of this colony were genetically differentiated from 
all others (G-tests, $P<0.0001)$ and probably belonged to a distinct colony (Fig. 2b, open circle). Interestingly, some of the distant collection points from trees were not genetically differentiated. The 14 collection points along Boulevard de La Madeleine were not significantly differentiated from the two collection points further along the boulevard $1200 \mathrm{~m}$ away (Fig. 2b, open triangles). Therefore, there were five distinct colonies from trees along the boulevard. We also should notice that the collection point isolated in the middle of the large colony in La Madeleine (Fig. 2b, open circle) was not significantly differentiated from the three collection points $8 \mathrm{a}, 8 \mathrm{~b}$ and $8 \mathrm{c}$. These distant collection points were treated as separate colonies because of the presumed lack of connection to the genetically similar colonies. Hence, 14 colonies were identified in Paris and were used in further analyses.

\section{Colony breeding system and genetic structure}

Despite the presence of up to nine and six alleles per locus in the Oléron and Paris populations, respectively (Table 1), we found at most four alleles at any of the markers in all the sampled colonies. Despite the low variability of the loci, more detailed analyses revealed that worker genotypes were inconsistent with simple families comprised of pairs of primary reproductives and their offspring. In the Oléron region, nine of the 12 colonies had more than four worker genotypes at one to four loci. The three other colonies had genotypes consistent with simple families, but the genotype distributions were significantly different from the ones expected if workers were the offspring of a pair of reproductives (G-test across all loci, $P<0.05)$. In the city of Paris, 12 of the 14 colonies had more than four genotypes, and frequently with as many as seven to 10 genotypes at one or more loci. Another colony had workers showing two homozygote and two heterozygote genotypes while three alleles were present, and the last one had genotype frequencies deviating significantly from expected in simple families ( $G$-test across all loci, $P<0.0001)$. Together, these results indicate that all sampled colonies in both Oléron and Paris had more than two reproductive individuals that most likely were the descendants of two reproductives.

The extended family structure was confirmed by the relatedness and F-statistic estimates. Somewhat surprisingly, the average relatedness among colonymates $(r)$ was as high as 0.62 in colonies from the Oléron region and 0.32 in colonies from the city of Paris (Table 2). Both values differ significantly from zero. However, the high relatedness value in Oléron is largely caused by inbreeding and/or spatial genetic differentiation, which results in a high and significant $F_{\mathrm{IT}}$. Indeed, the inbreeding-adjusted estimate of relatedness $\left(r^{*}\right)$ was small in both regions, suggesting that many neotenics reproduce in each colony (Table 2 ).

The $F_{\mathrm{CT}}$ estimates were significantly greater than zero in the two regions, as revealed by the confidence intervals generated by bootstrapping over loci (Table 2 ) and by permutation tests $(P<0.001)$. A significant genetic differentiation among colonies was expected, as genetic dissimilarity of collection points was a criterion for establishing colony boundaries. However, the $F_{\mathrm{CT}}$ estimates were very high, indicating a strong genetic differentiation between colonies. $F_{\text {IT }}$ estimates over all loci were high and significantly positive in both Oléron and Paris (Table 2; permutation tests, $P<0.001)$. Such a high deficit of heterozygotes overall indicates nonrandom mating and inbreeding at the population level. Interestingly, the $F_{\text {IC }}$ estimates were close to and not significantly different from zero in Paris (Table 2; the confidence interval overlaps with zero, and $P=0.50$ in the permutation test). A small positive $F_{\text {IC }}$ was also found in the Oléron region, but the permutation test indicated that it was just significant $(P=0.032)$, suggesting a slight deficit of heterozygous within colonies. The low $F_{\text {IC }}$ values suggest that there are many breeders in each colony, and that mating occurs almost at random within colonies. Interestingly, relatedness, $F_{\mathrm{CT}}$, and $F_{\mathrm{IT}}$ were significantly lower in Paris than in Oléron, as demonstrated by the non-overlapping confidence intervals, all of which are consistent with higher numbers of neotenics in the Paris colonies.

\section{Isolation by distance}

There was significant isolation by distance among collection points within two of the three largest colonies from the small spatial scale in the two regions. Specifically, there was a significant positive correlation between geographical distance and genetic differentiation between pairs of collection points in the colonies of the Saumonards (Fig. 3A; Mantel test: $n=24, r=0.20, P=0.01$ ) and Boulevard de la Madeleine (Fig. 3B; Mantel test: $n=14, r=0.22, P=0.033$ ), but not in the colony of La Gautrelle (Mantel test: $n=8$, $r=-0.051, P=0.41)$.

Table $2 F$-statistics, worker relatedness estimates $(r)$ and inbreeding-adjusted relatedness estimates $\left(r^{*}\right)$ in Oléron and Paris. Confidence intervals of $95 \%$ are shown in parentheses. The sample size $n$ refers to the number of colonies studied in each population

\begin{tabular}{lrlllr}
\hline & \multicolumn{1}{c}{$F_{\mathrm{IC}}$} & $F_{\mathrm{IT}}$ & $F_{\mathrm{CT}}$ & $r$ & $r^{*}$ \\
\hline Oléron region $(n=12)$ & $0.032(-0.017-0.079)$ & $0.386(0.308-0.449)$ & $0.366(0.308-0.449)$ & $0.618(0.564-0.672)$ & 0.138 \\
Paris $(n=14)$ & $-0.001(-0.025-0.022)$ & $0.168(0.084-0.262)$ & $0.169(0.082-0.272)$ & $0.322(0.259-0.385)$ & 0.048 \\
\hline
\end{tabular}



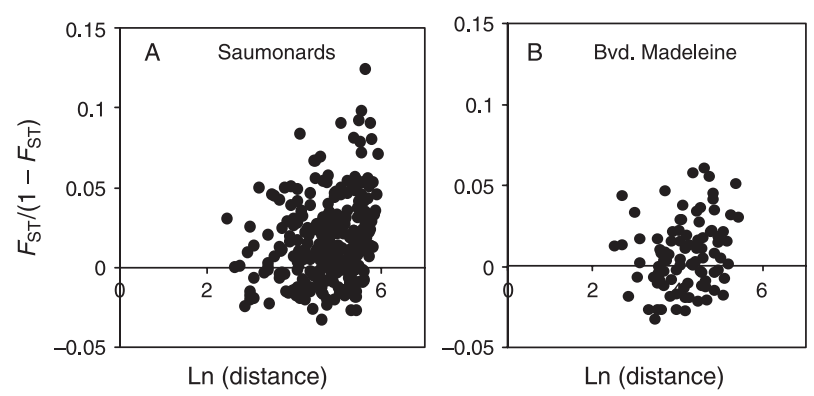

Fig. 3 Isolation-by-distance analysis within the two largest colonies. The relationship between pairwise estimates of $F_{\mathrm{ST}} /\left(1-F_{\mathrm{ST}}\right)$ and geographical distance is shown between pairs of collection points (stumps) within the colony of Saumonards in Oléron $(r=0.20$, $P=0.01$, Mantel test) and between pairs of collection points (alignment trees) within the colony of Boulevard de la Madeleine in Paris $(r=0.22, P=0.033$, Mantel test).

\section{Genetic diversity in natural and urban regions}

There was significant genetic differentiation between the Oléron region and Paris $\left(F_{\mathrm{ST}}=0.102,95 \% \mathrm{CIs}=0.040-0.221\right)$. The number of alleles was significantly higher in Oléron region than in Paris (Table 1, $t$-test, one-tailed, $P=0.03$ ). However, the level of gene diversity $H_{\mathrm{S}}$ was not significantly different between the two populations $\left(H_{\mathrm{S}}=0.34\right.$ and 0.42 for Oléron and Paris, respectively; permutation test, two-sided, $P=0.31$ ).

\section{Discussion}

The genetic data indicate that all the study colonies were headed by large numbers of inbred neotenic reproductives. The genotype distribution within colonies strongly suggests that there were always more than two breeders. However, the presence of at most four alleles in each colony is compatible with the hypothesis that all breeders from a colony descend from a single pair of primary reproductives. The $F$-statistics are fully consistent with colonies being headed by multiple neotenic reproductives inbred for several generations. Taken together, the high and significant $F_{\mathrm{IT}}, F_{\mathrm{CT}}$ very close to $F_{\mathrm{IT}}$, and $F_{\mathrm{IC}}$ close to zero indicate that there are many related breeders in each colony, which results in significant genetic differentiation among colonies and inbreeding. The low inbreeding-adjusted relatedness estimates confirms that there are many breeders in each colony. Moreover, we observed many neotenic reproductives when sampling workers, up to two dozen in some single collection points, even in covered galleries on tree bark. When compared to the results of simulations corresponding to various types of breeding systems (Thorne et al. 1999; Bulmer et al. 2001), our relatedness and $F$-statistics coefficients match best with the situation in which mating occurs among multiple neotenics (from 10 to 200) who are descended from a pair of primary reproductives and then mate within colonies for at least three generations (e.g. $F_{\mathrm{IT}}=0.34, F_{\mathrm{CT}}=0.34$ and $F_{\text {IC }}=0.00$ for 200 females and 100 males; Thorne et al. 1999).

Our finding of only neotenic-headed colonies contrasts with the variability of breeding systems in other subterranean termites. In the related North American species Reticulitermes flavipes, a population from central North Carolina contains some $75 \%$ of colonies consisting of simple families, about $25 \%$ contain low numbers of neotenic reproductives descended from simple families and 1-2\% are mixed families (Vargo 2003a, b; DeHeer \& Vargo 2004; Vargo \& J. Carlson, unpublished); whereas in a Massachusetts population, most colonies contain numerous neotenics, about $33 \%$ are simple families and about $10 \%$ are mixed families (Bulmer et al. 2001). The frequency of simple families was also variable in French populations of Reticulitermes grassei (Clément 1981; DeHeer et al., unpublished). In Coptotermes formosanus, $90 \%$ of colonies infesting structures in Nagasaki, Japan, consisted of simple families (Vargo et al. 2003). In a previous study of the La Coubre forest population of Reticulitermes santonensis based on a single polymorphic allozyme marker, Clément (1981) reported a high proportion of colonies with worker genotypes consistent with simple families. The difference between these previous results and our results might be caused by a shift in colony genetic structure over time, to geographical differences, or to the higher resolution of multiple microsatellite loci over a single allozyme locus.

The prevalence of neotenic reproduction in R. santonensis is reflected by data on demography and seasonal changes in caste proportions. At the time of swarming, the proportion of brachypterous nymphs, which molt into neotenics, was much higher than nymphs with long wing buds, which develop into alates (Vieau 1996). Interestingly, the alate stage is also relatively rare in $R$. flavipes colonies from the extreme northern edge of its distribution in the United States, where the species is presumably introduced, which suggests that the nymphs in this region also develop into neotenics (Esenther 1969; Grace 1996). In contrast, neotenics did not exceed $0.1 \%$ of the biomass in $R$. flavipes colonies from Mississippi (US) while nymphs with long wing buds attained $13 \%$ of the biomass and showed two peaks of abundance in early fall and early summer (Howard \& Haverty 1981). Similar changes in the breeding system between native and introduced populations have been found in three Australian Coptotermes species. Functional neotenics are infrequent in the native range, but appear to be the means by which colonies grow and spread in introduced populations of New Zealand (Lenz \& Barrett 1982).

Our data indicate that in both natural and urban regions, colonies of $R$. santonensis can be spatially expansive, in accordance with a mark-release-recapture experiment which has revealed that the foraging range of a single colony exceeded $1000 \mathrm{~m}^{2}$ (Paulmier et al. 1997). Occurrence of large 
and populous colonies is consistent with the presence of extended families headed by numerous neotenics. A recent laboratory study using isolated groups of workers showed that $R$. santonensis workers could differentiate into male and female neotenics in 5 months and produce eggs 3 months later (Kutnik et al., unpublished). Even if individual neotenic female lays eggs at a lower rate than primary queens, the combined reproductive capacity of large numbers of neotenics can far exceed that of a single queen (Myles \& Nutting 1988; Thorne 1998; Long et al. 2003; Grube \& Forschler 2004). With a large population size, colonies can form extensive networks of underground tunnels leading to the simultaneous exploitation of numerous food resources.

We found significant isolation by distance among the collection points within the two largest colonies, indicating that the workers within expansive colonies are not genetically homogeneous. This suggests that there were spatially separated reproductive centres, among which there was somewhat limited movement of workers and neotenics. In spatially expansive colonies, nymphs might be released from pheromonal inhibition (reviewed in Henderson 1998), permitting their differentiation into secondary reproductives and hence the development of daughter satellite nests (Myles 1999). Whether such daughter nests can completely separate from the mother colony and become autonomous colonies remains to be determined, but so far genetic data have not supported the view that budding is a common mode of reproduction in Reticulitermes spp. (Bulmer \& Traniello 2002; Vargo 2003a; DeHeer \& Vargo 2004).

The nondifferentiation of some distant colonies in the urban population and the significantly lower F-statistics values in Paris than in Oléron suggest that humans contribute to the dispersal and fragmentation of colonies in the city. This phenomenon has already been reported in the invasive species Coptotermes formosanus in which a lack of significant viscosity was found in introduced populations in New Orleans, Hawaii, and southern Japan (Husseneder et al., unpublished; Vargo et al. 2003). Moreover, swarming is still observed in Paris (Lohou, personal observation), so a few alates of $R$. santonensis might occasionally disperse over long distances and colonize new areas. In $R$. flavipes populations in central North Carolina, long-range mating flights appear responsible for the extensive gene flow observed in this region at scales of 1-20 km (Vargo 2003a).

Finally, we found a moderate level of genetic differentiation between Paris and Oléron regions, no doubt because the populations are too far apart to permit natural gene flow. The higher number of alleles in the Oléron region than in Paris is consistent with the hypothesis that $R$. santonensis was first introduced to western France, from which it was then transported to eastern and northern cities. Studies involving more populations will be needed to test this scenario.

The results of this study, in combination with the intraand interspecific patterns of variation in breeding systems in other subterranean termites, suggest an association between the prevalence of reproduction through neotenics and the invasion of new habitats with harsh climatic conditions. The diverse and flexible breeding systems found in subterranean termites might pre-adapt them to invade new or marginal habitats. In France, where R. santonensis is likely to have been introduced, colonies tend to be very large and have high numbers of neotenics, which probably facilitates the spread of colonies by human transport and contributes to the ecological success of $R$. santonensis in urban areas. A study using mitochondrial DNA and microsatellite markers is currently being conducted to establish conclusively whether R. santonensis is an introduced form of $R$. flavipes, and if so, whether there has been a significant change in the breeding system from the population of origin. Identifying the population of origin, whether it be North America or somewhere else, will allow comparative studies of the breeding systems to determine if the success of $R$. santonensis in France and other places is caused by the characteristics of the breeding system in the original population, or is a consequence of the introduction and subsequent colonization in these new areas. In this regard, studies of other $R$. santonensis populations, such as in Santiago and Valparaiso, Chile, or in Hamburg, Germany, as well as other introduced populations of $R$. flavipes, such as in Toronto, Canada, should help answer these questions.

\section{Acknowledgements}

We are grateful to Florent Vieau and Erick Dronnet for their help in field collections. The 'Section de Lutte contre les termites' (SMASH, Paris) and the following PCOs (HIE Piguy, Hygiène Office and Techmohygiène) kindly provided some Parisian samples. We thank Marc C.P. Ohresser for his help in earlier experiments. We are grateful to Chris J. DeHeer and Georges Periquet for fruitful discussions and comments on the manuscript. This work was supported in part by a contract between the Centre de la Recherche Scientifique (CNRS) and the city of Paris (Direction des Parcs, Jardins et Espaces verts) and a joint grant ( $\left.\mathrm{n}^{\circ} 14574\right)$ between the CNRS and the US National Science Foundation to AGB and ELV. Michel Chapuisat is funded by the Swiss National Science Foundation (grant 31-61934.00).

\section{References}

Austin JW, Szalanski AL, Uva P, Bagnères AG, Kence A (2002) A comparative genetic analysis of the subterranean termite genus Reticulitermes. Annals of the Entomological Society of America, 95, 753-760.

Bagnères A-G, Clément J-L, Blum MS, Severson RF, Joulie C, Lange C (1990) Cuticular hydrocarbons and defensive compounds of Reticulitermes flavipes (Kollar) and R. santonensis (Feytaud): polymorphism and chemotaxonomy. Journal of Chemical Ecology, 16, 3213-3244.

Bulmer MS, Adams ES, Traniello JFA (2001) Variation in colony structure in the subterranean termite Reticulitermes flavipes. Behavioral Ecology and Sociobiology, 49, 236-243. 
Bulmer MS, Traniello JFA (2002) Lack of aggression and spatial association of colony members in Reticulitermes flavipes. Journal of Insect Behavior, 15, 121-126.

Chapman RE, Bourke AFG (2001) The influence of sociality on the conservation biology of social insects. Ecology Letters, 4, 650662.

Chapuisat M, Bocherens S, Rosset H (2004) Variable queen number in ant colonies: no impact on queen turnover, inbreeding, and population genetic differentiation in the ant Formica selysi. Evolution, 58, 1064-1072.

Chapuisat M, Goudet J, Keller L (1997) Microsatellites reveal high population viscosity and limited dispersal in the ant Formica paralugubris. Evolution, 51, 475-482.

Clément J-L (1981) Enzymatic polymorphism in the European populations of various Reticulitermes species (Isoptera). In: Biosystematics of Social Insects (eds Howse PE, Clément JL), pp. 4962. Academic Press, London.

Clément J-L, Bagnères A-G, Uva P et al. (2001) Biosystematics of Reticulitermes termites in Europe: morphological, chemical and molecular data. Insectes Sociaux, 48, 202-215.

DeHeer CJ, Vargo EL (2004) Colony genetic organization and colony fusion in the termite Reticulitermes flavipes as revealed by foraging patterns over time and space. Molecular Ecology, 13, 431-441.

Dronnet S, Bagnères A-G, Juba TR, Vargo EL (2004) Polymorphic microsatellite loci in the European subterranean termite, Reticulitermes santonensis Feytaud. Molecular Ecology Notes, 4, 127-129.

Esenther GR (1969) Termites in Wisconsin. Annals of the Entomological Society of America, 62, 1275-1284.

Everett RA (2000) Patterns and pathways of biological invasions. Trends in Ecology \& Evolution, 15, 177-178.

Feytaud J (1924) Le termite de Saintonge. Compte-Rendus de l'Académie Des Sciences, 171, 203-205.

Gay FJ (1969) Species introduced by man. In: Biology of Termites, vol. 1 (eds Krishna K, Weesner FM), pp. 459-494. Academic Press, New York and London.

Giraud T, Pedersen JS, Keller L (2002) Evolution of supercolonies: the Argentine ants of southern Europe. Proceedings of the National Academy of Sciences of the United States of America, 99, 6075-6079.

Goodisman MAD, Crozier RH (2002) Population and colony genetic structure of the primitive termite Mastotermes darwiniensis. Evolution, 56, 70-83.

Goudet J (1995) FSTAT (version 1.2): a computer program to calculate F-statistics. Journal of Heredity, 86, 485-486.

Grace JK (1996) Temporal and spatial variation in caste proportions in a northern Reticulitermes flavipes colony (Isoptera: Rhinotermitidae). Sociobiology, 28, 225-231.

Grube S, Forschler BT (2004) Census of monogyne and polygyne laboratory colonies illuminates dynamics of population growth in Reticulitermes flavipes (Isoptera: Rhinotermitidae). Annals of the Entomological Society of America, 97, 466-475.

Hamilton WD (1964) The genetic evolution of social behaviour. Journal of Theoretical Biology, 71, 1-52.

Henderson G (1998) Primer pheromones and possible soldier caste influence on the evolution of sociality in lower termites. In: Pheromone Communication in Social Insects: Ants, Wasps, Bees and Termites (eds Vander Meer RK, Breed MD, Winston ML, Espelie KE), pp. 314-330. Westview Press, Oxford.

Holway DA, Lach L, Suarez AV, Tsutsui ND, Case TJ (2002) The causes and consequences of ant invasions. Annual Review of Ecology and Systematics, 33, 181-233.
Howard RW, Haverty MI (1981) Seasonal variation in caste proportions of field colonies of Reticulitermes Flavipes (Kollar). Environmental Entomology, 10, 546-549.

Jenkins TM, Dean RE, Verkerk R, Forschler BT (2001) Phylogenetic analyses of two mitochondrial genes and one nuclear intron region illuminate European subterranean termite (Isoptera: Rhinotermitidae) gene flow, taxonomy, and introduction dynamics. Molecular Phylogenetics and Evolution, 20, 286-293.

Lainé LV, Wright DJ (2003) The life cycle of Reticulitermes spp. (Isoptera: Rhinotermitidae): what do we know? Bulletin of Entomological Research, 93, 267-278.

Lenz M, Barrett RA (1982) Neotenic formation in field colonies of Coptotermes lacteus (Frogatt) in Australia, with comments on the roles of neotenics in the genus Coptotermes (Isoptera: Rhinotermitidae). Sociobiology, 7, 47-59.

Lewis PO, Zaykin D (2000) GENETIC DATA ANALYSIS: computer program for the analysis of allelic data, Version 1.1.

Lohou C, Burban G, Clément J-L, Jecquel M, Leca J-L (1997) Protection des arbres d'alignement contre les termites souterrains; l'expérience menée à Paris. Phytoma, 492, 42-44.

Long CE, Thorne BL, Breisch NL (2003) Termite colony ontogeny: a long-term assessment of reproductive lifespan, caste ratios and colony size in Reticulitermes flavipes (Isoptera: Rhinotermitidae). Bulletin of Entomological Research, 93, 439-445.

Luchetti A, Trenta M, Matovani B, Marini M (2004) Taxonomy and phylogeny of north mediterranean Reticulitermes termites (Isoptera, Rhinotermitidae): a new insight. Insectes Sociaux, 51, 117-122.

Mantel N (1967) The detection of disease clustering and a generalized regression approach. Cancer Research, 27, 209-220.

Marini M, Mantovani B (2002) Molecular relationships among European samples of Reticulitermes (Isoptera, Rhinotermitidae). Molecular Phylogenetics and Evolution, 22, 454-459.

Moller H (1996) Lessons for invasion theory from social insects. Biological Conservation, 78, 125-142.

Myles TG (1999) Review of secondary reproduction in termites (Insecta: Isoptera) with comments on its role in termite ecology and social evolution. Sociobiology, 33, 1-94.

Myles TG, Nutting WL (1988) Termite eusocial evolution: a reexamination of Bartz's hypothesis and assumptions. Quarterly Review of Biology, 63, 1-23.

Nei M (1987) Molecular Evolutionary Genetics. Columbia University Press, New York.

Pamilo P (1985) Effect of inbreeding on genetic relatedness. Hereditas, 103, 195-200.

Pamilo P (1989) Estimating relatedness in social groups. Trends in Ecology E Evolution, 4, 353-355.

Paulmier I, Vauchot B, Pruvost A-M et al. (1997) Evaluation of two populations of Reticulitermes santonensis De Feytaud (Isoptera) by triple mark-recapture procedure. 28th Annual Meeting of the International Research Group on Wood Preservation, 2-5, 25-30 May 1997, Whistler, British Columbia, Canada.

Pedersen JS, Boomsma JJ (1999) Genetic analysis of colony structure in polydomous and polygynous ant populations. Molecular Ecology, 8, 577-587.

Pimentel D, Lach L, Zuniga R, Morrison D (2000) Environmental and economic costs of non-indigenous species in the United States. Bioscience, 50, 53-65.

Porter SD, Williams DF, Patterson RS, Fowler HG (1997) Intercontinental differences in the abundance of Solenopsis fire ants (Hymenoptera: Formicidae): escape from natural enemies? Environmental Entomology, 26, 374-384. 
de Quatrefages A, (1843) Note sur les termites de La Rochelle. Annales de la Société de Zoologie, 30, 16.

Queller DC, Goodnight KF (1989) Estimating relatedness using genetic markers. Evolution, 43, 258-275.

Raymond M, Rousset F (1995) GENEPOP (version 1.2): a population genetics software for exact tests and ecumenism. Journal of Heredity, 86, 248-149.

Ross KG (1993) The breeding system of the fire ant Solenopsis invicta: effects on colony genetic structure. American Naturalist, 141, 554-576.

Ross KG (2001) Molecular ecology of social behaviour: analyses of breeding systems and genetic structure. Molecular Ecology, 10, 265-284.

Ross KG, Vargo EL, Keller L (1996) Social evolution in a new environment: The case of introduced fire ants. Proceedings of the National Academy of Sciences of the United States of America, 93, 3021-3025.

Rousset F (1997) Genetic differentiation and estimation of gene flow from $F$-statistics under isolation by distance. Genetics, 145, 1219-1228.

Sambrook F, Fritsch EF, Maniatis T (1989) Molecular Cloning: A Laboratory Manual. Cold Spring Harbor Laboratory Press, New York.

Slatkin M (1993) Isolation by distance in equilibrium and nonequilibrium populations. Evolution, 47, 264-279.

Su N-Y, Scheffrahn RH (1990) Economically important termites in the United States and their control. Sociobiology, 17, 77-94.

Thorne BL (1998) Biology of subterranean termites of the genus Reticulitermes. In: NPCA Research Report on Subterranean Termites. pp. 1-30. National Pest Control Association, Dunn Loring, Virginia.

Thorne BL, Traniello JFA, Adams ES, Bulmer M (1999) Reproductive dynamics and colony structure of subterranean termites of the genus Reticulitermes (Isoptera Rhinotermitidae), a review of the evidence from behavioral, ecological, and genetic studies. Ethology Ecology and Evolution, 11, 149-169.

Tsutsui ND, Suarez AV, Grosberg RK (2003) Genetic diversity, asymmetrical aggression, and recognition in a widespread invasive species. Proceedings of the National Academy of Sciences of the United States of America, 100, 1078-1083.

Tsutsui ND, Suarez AV, Holway DA, Case TJ (2000) Reduced genetic variation and the success of an invasive species. Proceedings of the National Academy of Sciences of the United States of America, 97, 5948-5953.

Uva P, Clément J-L, Austin JW et al. (2004) Origin of a new Reticulitermes termite (Isoptera, Rhinotermitidae) inferred from mitochondrial and nuclear DNA data. Molecular Phylogenetics and Evolution, 30, 344-353.

Vargo EL (2000) Polymorphism at trinucleotide microsatellite loci in the subterranean termite Reticulitermes flavipes. Molecular Ecology, 9, 817-819.
Vargo EL (2003a) Hierarchical analysis of colony and population genetic structure in the eastern subterranean termite, Reticulitermes flavipes, using two classes of molecular markers. Evolution, 57, 2805-2818.

Vargo EL (2003b) Genetic structure of Reticulitermes flavipes and $R$. virginicus (Isoptera, Rhinotermitidae) colonies in an urban habitat and tracking of colonies following treatment with hexaflumuron bait. Environmental Entomology, 32, 1271-1282.

Vargo EL, Husseneder C, Grace JK (2003) Colony and population genetic structure of the Formosan subterranean termite, Coptotermes formosanus, in Japan. Molecular Ecology, 12, 2599-2608.

Vieau F (1993) Le Termite de Saintonge Reticulitermes santonensis Feytaud: termite urbain. Bulletin de la Société Zoologique Française, 118, 125-133.

Vieau F (1996) Les variations saisonnières des castes chez le termite Reticulitermes santonensis Feytaud (Isoptera: Rhinotermitidae) dans un biotope de l'ouest de la France. Annales Société Entomologique Française, 32, 207-216.

Vieau F (2001) Comparison of the spatial distribution and reproductive cycle of Reticulitermes santonensis Feytaud and Reticulitermes lucifugus grassei Clément (Isoptera, Rhinotermitidae) suggests that they represent introduced and native species, respectively. Insectes Sociaux, 48, 57-62.

Weir BS (1996) Genetic Data Analysis II. Sinauer Associates, Sunderland, Massachusetts.

Weir BS, Cockerham CC (1984) Estimating F-statistics for the analysis of population structure. Evolution, 38, 1358-1370.

Wright S (1951) The genetical structure of populations. Annals of Eugenics, 15, 323-354.

Ye W, Lee C-Y, Scheffrahn RH, Aleong JM, Su N-Y, Bennett GW, Scharfa ME (2004) Phylogenetic relationships of nearctic Reticulitermes species (Isoptera: Rhinotermitidae) with particular reference to Reticulitermes arenincola Goellnerq. Molecular Phylogenetics and Evolution, 30, 815-822.

This study is part of the PhD dissertation of Stéphanie Dronnet, who received her degree in Ecology at Paris 6 University. She is a temporary assistant at the University of Tours, investigating in population and colony genetic structure of social insects. During her $\mathrm{PhD}$ she was also interested how genetic structure may influence cuticular hydrocarbon variations among and within colonies. Michel Chapuisat studies the evolution of insect societies, with a particular interest in breeding systems, population genetics and sex allocation. Edward Vargo investigates breeding systems and population genetic structure of subterranean termites. Caroline Lohou is the Ingenior in charge of the tree protection for the city of Paris. Anne-Geneviève Bagnères research focuses on biology, population genetics, phylogenetics and chemical ecology of the European termites. 